DOI: $10.4274 /$ tpa.46.74

\title{
Diyarbakır'da hasta yenidoğanın taşınması konusunda yapılan iyileştirme çalışmaları ve bebeklere yansımaları
}

\section{The effects of improvement efforts on regional neonatal transport conditions in Diyarbakır}

\author{
Sinan Uslu, Bedri Aldudak*, Hamuş Özdemir** \\ Şişli Ettal Eğitim ve Araştırma Hastanesi, Yenidoğan Kliniği, Istanbul, Türkiye \\ *Diyarbakır Çocuk Hastalıkları Hastanesi, Yenidoğan Kliniği, Diyarbakır, Türkiye \\ **Yenidoğan Yoğun Bakım Birimi Sorumlu Hemşıiresi, Diyarbakır Çocuk Hastallkları Hastanesi, Yenidoğan Kliniği, Diyarbakır, Türkiye
}

\section{Özet}

Amaç: Hasta yenidoğanların taşınma koşullarını düzeltmeye yönelik yapılan iyileştirme çalışmalarının, Diyarbakır Çocuk Hastalıkları Hastanesi Yenidoğan Yoğun Bakım Birimi'ne sevk edilen hasta yenidoğanların taşınma koşulları ve ölüm hızı üzerine etkilerini belirlemektir.

Gereç ve Yöntem: Yenidoğan Yoğun Bakım Birimi'ne 1 Mart 2007 - 31 Ağustos 2007 (1. Dönem, Grup 1) ve 1 Ocak 2008 - 30 Nisan 2008 tarihleri (2.Dönem, Grup 2) arasında sevk edilen yenidoğanların taşınma koşulları saptandı ve yapılan iyileştirme çalışmaları sonrasında iki dönem arasındaki farklılıklar karşılaştırıldı (etik kurul onay tarihi:28.02.2007). Elde edilen veriler SPSS (Social Package for Social Sciences) 11,5 programı kullanılarak analiz edildi. İstatiksel değerlendirmede Student t ve ki-kare testleri kullanıldı.

Bulgular: Çalışmanın 1.döneminde 1525, 2.döneminde ise 927 hasta yatırıldı. Her iki gruptaki hastaların demografik özellikleri ve yatış tanıları benzerdi. Hasta yenidoğanların taşınma koşullarını düzeltmeye yönelik gerçekleștirilen iyileștirme çalışmaları sonrasında 2. grupta sevk öncesi haberleşme, yeterli epikriz yazılması, taşınma sırasında ambulans ve taşıyıcı küvöz kullanılması, doğum raporu, kimlik ve cinsiyetin belirtilmesi, uygun intravenöz sıvıların takılması ve entübasyon gereksinimi olan hastaların entübe edilme sıklığının arttığı; hipotermi, hipoglisemi, hipotansiyon ve dolaşım bozukluğu gibi bulguların görülme sıklığının ise azaldığı saptandı. Hastaların ortalama "transport fizyolojik stabilite risk indeksi (Transport

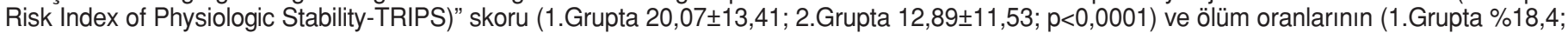
2.Grupta \%14,1; $p<0,007$ ) iyileştirme çalışmaları sonrasında olumlu yönde değiştiği saptandı.

Çıarımlar: Diyarbakır bölgesinde hasta yenidoğanların taşınma koşulları, gerçekleştirilen iyileştirme çalışmaları sonucunda belirgin olarak düzeldi. Ülkemizde bölgesel yenidoğan taşıma sistemlerinin oluşturulması temel sağlık politikalarında acil eylem planı olarak ele alınmalıdır. (Türk Ped Arş 2011; 46: 196-201)

Anahtar sözcükler: Bölgeselleşme, perinatal bakım, transport, yenidoğan

\section{Summary}

Aim: To determine the effects of the employments towards improving the status of neonatal transport on conditions and mortality of newborns who were referred to Diyarbakır Children Hospital, Neonatal Intensive Care Unit (NICU).

Material and Method: The transport conditions of newborns referred to NICU were determined before (between March 1, 2007-August 31, 2007; $1^{\text {st }}$ period, Group 1) and after (January 1, 2008 to April 30, 2008; 2nd period, Group 2) improving employments. The differences between the two periods were compared in terms of medical and paramedical findings (Date of ethics committee approval: 28.02.2007). Social Package for Social Sciences (SPSS) 11.5 program was used to analyze the data. Student's t and chi-square tests were used for statistical evaluation.

Results: A total of 1525 patients were hospitalized in the first period whereas 927 in the second period. Diagnoses and demographic characteristics of infants were similar in both groups. After the improvement employments were carried out on neonatal transport the $2^{\text {nd }}$ group had a higher incidence of positive findings, such as presence of pre-transport communication, detailed discharge report, birth report, determination of gender and identity, usage of ambulance and transport incubator, proper usage of intravenous fluids, and frequency of intubation of patients needing to be intubated. The frequency of hypothermia, hypoglycemia, hypotension and circulatory disorder were lower in the $2^{\text {nd }}$ group. Transport Risk Index of Physiologic Stability-TRIPS score $(20.07 \pm 13.41$ vs $12.89 \pm 11.53 ; p<0.0001)$ and mortality rate $(\% 18.4$ vs $\% 14.1 ; p=0.007)$ were significantly higher in among infants of the 1 st group.

Conclusions: Neonatal transport conditions have improved as a result of improvement employments in Diyarbakir region. Regional neonatal transport system by ensuring the rational establishment of conditions should be approached as an emergency action plan in basic health policies. (Turk Arch Ped 2011; 46: 196-201)

Key words: Newborn, perinatal care, regionalization, transport

Yazışma Adresi/Address for Correspondence: Dr. Sinan Uslu, Şişli Etfal Eğitim ve Araştırma Hastanesi, Yenidoğan Kliniği Şişli, 34360 İstanbul, Türkiye Tel.: +90 21237350 00/6601 E-posta: sinanuslumd@hotmail.com Geliş Tarihi/Received: 03.01.2011 Kabul Tarihi/Accepted: 06.04.2011 


\section{Giriş}

Son 10 yılda yenidoğan yoğun bakım birimlerinin (YYBB) tıbbi teknoloji ve bakım koşullarının baş döndürücü hızla gelişmesi hasta yenidoğanların sağ kalımlarını artırmış ve seyirlerini belirgin olarak düzeltmiştir. Buna koşut olarak perinatal bakım kavramı büyük önem kazanmıştır. Perinatal bakımın niteliği anne ve bebek ölüm hızlarının ve sakatlık oranlarının azaltılmasına etki eden temel etmendir (1). Çağdaş ülkeler perinatal bakım şartlarını bölgeselleşme programı ilkelerine dayanarak belirlemişlerdir. Yenidoğanın taşınması ise bölgeselleştirilmiş perinatal sağlık sisteminin en önemli öğesidir (2). Perinatal bakım hizmetlerinin düzenlenmesi, bölgeselleşme ve yenidoğanın taşınması kavramlarının gelişmesi ve öneminin farkına varılması sonucunda pek çok çağdaş ülkede ulusal politikalar oluşturulmuştur (3-5). Ülkemizde ise YYBB bünyesinde tanı, tedavi ve bakım koşullarının hızla ilerlemesine karşın perinatal bölgeselleşmiş bakım ve hasta yenidoğanın taşınması konularında hukuksal ve yasal düzenlemeler yoktur.

Diyarbakır Çocuk Hastalıkları Hastanesi, başta Mardin, Batman, Siirt, Şırnak olmak üzere 15 ayrı ilden ve ilçelerinden (Bingöl, Şanlıurfa, Bitlis, Van, Adıyaman, Hakkari, Muş, Ağrı, Elazığ, Adana ve Tunceli), yoğun bakım ve riskli yenidoğan izlemi gerektiren bebeklerin sevk edilebildiği, her üç düzey bakım olanaklarına sahip 55 yataklı YYBB ve anne yanında riskli yenidoğanların takip ve tedavi gördüğü 50 yataklı riskli yenidoğan kliniği olan bir bölge hastanesidir. Bünyesinde doğum kliniği olmadığından tüm hastalarını dış merkezlerden kabul etmektedir. Bu nedenle özellikle YYBB'ye kabul edilen hasta yenidoğanların taşınması çok önemlidir.

Çalışmamızda hastanemiz YYBB'ye sevk edilen bebeklerin iki farklı zaman aralığındaki taşınma koşulları incelenerek, mevcut durumun iyileştirilmesine yönelik yapılan çalışmaların hasta yenidoğanın taşınma koşullarına etkileri araştııılı.

\section{Gereç ve Yöntem}

Diyarbakır Çocuk Hastalıkları Hastanesi YYBB'de 1 Mart 2007 - 31 Ağustos 2007 (1.Dönem, Grup 1) ve 1 Ocak 2008 - 30 Nisan 2008 tarihleri (2.Dönem, Grup 2) arasında yatırı- larak tedavi edilen yenidoğanların taşınmalarına ait özellikler saptandı ve taşıma koşullarını iyileştirme çalışmaları sonrasında iki dönem arasındaki farkılııklar değerlendirildi (etik kurul onay tarihi: 28.02.2007).

Hasta yenidoğanın taşınma koşullarının değerlendirilmesi ve verilerin standardizasyonu için mesai saatleri içinde ve dışında hastaların YYBB'ye kabul talimatı ve ekibi oluşturularak önceden hazırlanan forma bilgilerin eksiksiz olarak kayıt edilmesi sağlandı. Formda yer alan bilgiler hastaların aileleri ile yüz yüze görüşülerek, tıbbi kayıtlardan ve taşımayı gerçekleştiren sağlık çalışanlarından elde edildi. Hasta ile birlikte gönderilen tüm yazılı bilgiler, çalışma formunda yer alan klinik bulgular ve laboratuvar sonuçları kaydedildi. Hastaların demografik özellikleri, tanıları, taşıma öncesi haberleşme, yeterli epikriz varlığı, ambülans ve transport küvöz ile taşınma, doğum raporu-kimlik ve cinsiyet bilgileri, venöz yol açıklığı, entübasyon durumu, dolaşım bozukluğu, hipoglisemi, hipotermi ve hipotansiyon varlığı, ve TRIPS (Transport Risk Index of Physiologic Stability; Transport fizyolojik stabilite risk indeksi) skorları istatiksel olarak değerlendirildi.

\section{Tanımlamalar}

Taşıma öncesi haberleşme: Taşıma öncesi Diyarbakır Çocuk Hastalıkları Hastanesi YYBB'de çalışan hekimlerle yazılı veya sözlü olarak haberleşmenin sağlanması,

Yeterli epikriz varlığı: Hastayı sevk eden merkezin hazırladığı epikrizde demografik bilgilerin, klinik bulguların, yapılan girişim ve tetkiklerin, ön tanı, sevk nedeni ve sevki gerçekleştiren hekimin kaşe ve imzasının yer alması,

Doğum raporu: Anne ve bebek ad ve soyadı, doğumun gerçekleştiği merkezin adı, protokol numarası, cinsiyet bilgisi ve ilgili hekimin kaşe ve imzasının bulunması,

Kimlik ve cinsiyet varlığı: Bebeğe takılı olan bileklikte bebek ve anne ad-soyadı, kimlik ve cinsiyet bilgilerinin yazılmış olması,

Hipotermi: Hastaların birime getirildikleri anda koltuk altından ilk ölçülen (Microlife digital thermometer, model MT 3001, Microlife AG Swiss Corp., Widnay, Switz) vücut Sıcaklığının $36^{\circ} \mathrm{C}$ 'nin altında saptanması (6),

\section{Tablo 1. Transport fizyolojik stabilite risk indeksi skoru}

(TRIPS -Transport Risk Index of Phisiologic Stability)

Değișken

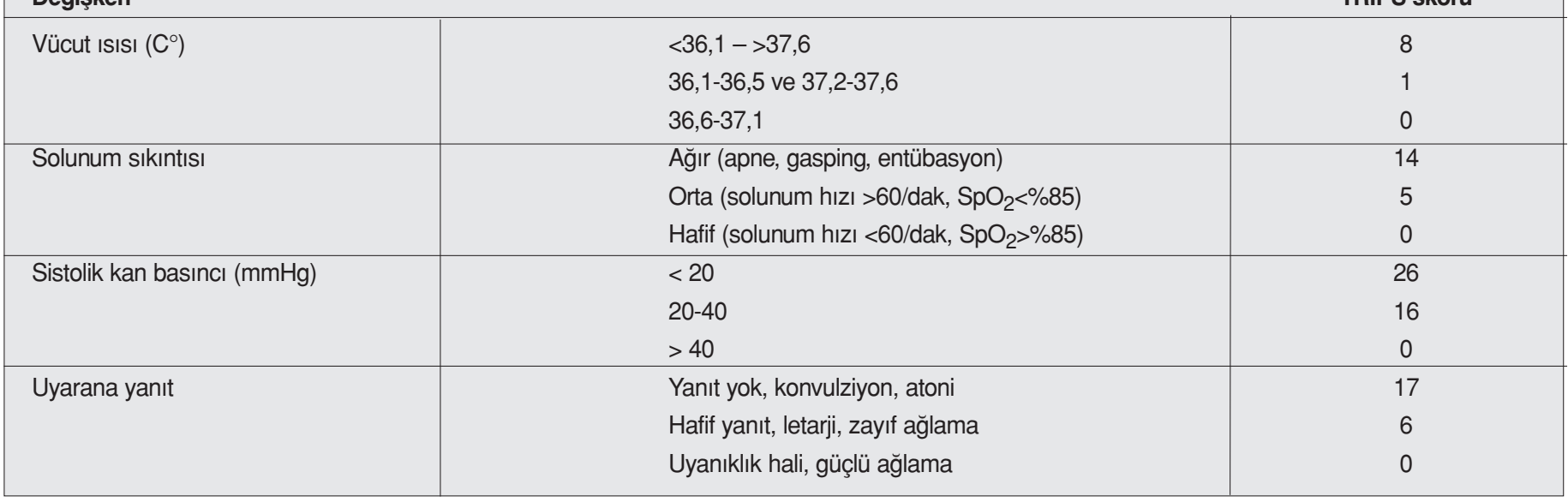


Hipoglisemi: Hastaların birime getirildikleri anda ilk ölçülen kan şekeri düzeyinin $45 \mathrm{mg} / \mathrm{dL}$ altında olması (7),

Hipotansiyon: Hastaların birime getirildikleri anda ilk elde edilen sistemik arteriyal kan basıncı ölçüm değerinin gebelik haftasına ve yaşa uygun standart değerlerin altında olması (8),

Çevresel dolaşım bozukluğu: Kapiler geri dolum süresinin uzaması (30. gebelik haftasından önce 5 saniye, diğer bebeklerde 3 saniyeyi aşması durumu) olarak tanımlandı (9).

Transport fizyolojik stabilite risk indeksi (Transport Risk Index of Physiologic Stability-TRIPS): Yenidoğan bebeklerin taşınma koşullarının YYBB'deki ölüm oranına (özellikle hastaneye yatıșın ilk yedi günündeki) etkilerini değerlendirmek üzere kullanıldı (10). Skorlama sistemi Tablo 1'de sunuldu. Skorlama hastayı serviste karşılayan hekim tarafından gerçekleștirildi.

Hasta yenidoğanların taşınma koşullarını iyileştirme çalışmaları aşağıdaki uygulamaları kapsamaktadır:

1. Yenidoğanın taşınması ile ilgili eğitim çalışmaları: Yenidoğan hastaların sevklerini gerçekleştiren kurumlardaki sağlık çalışanlarının eğitim toplantılarına katııımı Diyarbakır ili için Diyarbakır İI Sağlık Müdürlüğü'nün, Diyarbakır ili dışındaki merkezler için ise Diyarbakır Valiliği kanalıyla ilgili illerin valiliklerinin bildirimleriyle düzenlendi. Hizmet içi eğitim niteliği taşıyan toplantılar "Perinatal Bölgesel Bakımın Organizasyonu" adı ile, Diyarbakır Çocuk Hastalıkları Hastanesi Başhekimliği'nin ve Diyarbakır Çocuk Hastalıkları Hastanesi YYBB kliniğinin organizasyonunda çeşitli üniversitelerden öğretim üyelerinin katıımı ile gerçekleştirildi.

2. İlgili il sağlık müdürlükleri tarafından ambülans, taşıyıcı küvöz, intravenöz enfüzyon pompaları ve nabız oksimetrilerinin alımlarının yapılması ve/veya mevcut sayılarının artırıması sağlandı.

3. Büyük bölümünü Diyarbakır Çocuk Hastalıkları Hastanesi YYBB'de çalışanların oluşturduğu eğitimciler ile Yenidoğan Canlandırma Programları (YCP) gerçekleştirildi. Böylece sevk eden merkezlerle, sevkleri kabul eden merkezde çalışanlar arasındaki iletişim artııılı.

4. Diyarbakır Çocuk Hastalıkları Hastanesi YYBB çalışanları tarafından hazırlanan "Yenidoğan Transport Formu"nun hasta yenidoğanların sevki sırasında kullanımı zorunlu hale getirildi (resmi yazıșmalar sonucunda T.C. Sağlık Bakanlığı Tedavi Hizmetleri Genel Müdürlüğünün 21.11.2007 tarih ve 2413 sayılı yazısı ile ilgili valiliklere bildirimi yapılarak)

5. 01.01.2008 tarihinden itibaren uygunsuz koşullarda gerçekleştirilen sevklerin ilgili merkezlere geri bildirimleri Diyarbakır İ Sağılı Müdürlüğü ve Diyarbakır Valiliği kanalıyla resmi olarak gerçekleştirilmeye başlandı.

\section{İstatiksel değerlendirme}

Çalışmadan elde edilen verilerin istatistiksel incelemesi için SPSS (Statistical Package for Social Sciences) for Windows 11.5 programı kullanıldı. Araștırmada demografik özellikler "descriptive" istatistiksel analizi ile değerlendirildi. Normal dağılım gösteren değişkenlerin gruplar arası karşılaștırmasında Student $t$ testi kullanıldı. Kategorik değişkenlerin karşılaştııımasında ki-kare testi kullanıldı. Sonuçlar \% 95 güven aralığında, $p<0,05$ anlamlı olarak değerlendirildi.

\section{Bulgular}

Diyarbakır Çocuk Hastalıkları Hastanesi YYBB'ye çalışma süreleri boyunca toplam 2452 hasta sevki kabul edildi. Hastalardan $1525^{\prime} \mathrm{i}$, altı aylık birinci dönem (1 Mart 2007-31 Ağustos 2007), 927'si ise dört aylık ikinci dönem (1 Ocak 2008-30 Nisan 2008) süresince yatıııldı. Her iki gruptaki hastaların demografik özellikleri (Tablo 2) ve yatış tanıları (Tablo 3) benzerdi.

Hastaların gruplara göre taşınma koşullarına ait özellikleri Tablo 4'te sunuldu.

Hasta yenidoğanın taşınmasına yönelik gerçekleştirilen iyileştirme çalışmaları sonrasında sevk öncesi haberleşme, yeterli epikriz yazııması, taşıma sırasında ambülans ve taşıyıcı kuvöz kullanımı, doğum raporu, kimlik ve cinsiyet bilgileri varlığı, uygun intravenöz sıvıların takılması, entübasyon gereksinimi olan hastaların entübe edilmesi gibi olumlu bulguların saptanma oranı ikinci grup hastada anlamlı şekilde artış gösterdi. Dolaşım bozukluğu, hipotermi, hipoglisemi ve hipotansiyon gibi olumsuz bulgular ise anlamlı şekilde daha az oranda saptandı.

Tablo 2. Yenidoğan yoğun bakım birimine getirilen hastaların demografik özellikleri

\begin{tabular}{|c|c|c|c|}
\hline Hastaların özellikleri & 1. grup $(n=1525)$ & 2. grup $(n=927)$ & $p$ \\
\hline \multicolumn{4}{|l|}{ Cinsiyet, $\mathrm{n}(\%)$} \\
\hline $\mathrm{K} \mathrm{z}$ & $750(49,2)$ & $430(46,4)$ & 0,179 \\
\hline Erkek & $775(50,8)$ & $497(53,6)$ & \\
\hline Vücut ağırlığı*, g & $2519,7 \pm 899,3$ & $2558,7 \pm 873,2$ & 0,289 \\
\hline Gebelik yaşı*, hafta & $36,1 \pm 3,8$ & $36,3 \pm 3,9$ & 0,237 \\
\hline \multicolumn{4}{|l|}{ Doğum şekli, n (\%) } \\
\hline Vajinal & $949(62,2)$ & $562(60,6)$ & 0,428 \\
\hline Sezaryen & $576(37,8)$ & $365(39,4)$ & \\
\hline \multicolumn{4}{|l|}{ Sevk yeri, n (\%) } \\
\hline Diyarbakır il merkezi & $960(63)$ & $617(66,6)$ & 0,071 \\
\hline Diyarbakır il merkezi dışı & $565(37)$ & $310(33,4)$ & \\
\hline
\end{tabular}

* Değerler ortalama, \pm Standart sapma (SS) olarak verilmiştir 
Birinci gruptaki hastaların TRIPS skoru daha yüksek saptandı $(20,07 \pm 13,41$ puana karşlık 12,89 $\pm 11,53$ puan; $p<0,0001)$. Birinci gruptaki hastaların 280'i (\%18,4), ikinci gruptaki hastaların ise 131 'i $(\% 14,1)$ kaybedildi. Birinci gruptaki ölümlerin 216 'sı $(\% 77,1)$, ikinci gruptaki ölümlerin ise 64'ü $(\% 48,9)$ hastaneye yatışların ilk yedi gününde gerçekleşti. Genel ve ilk yedi günde gerçekleşen ölüm oranları birinci gruptaki bebeklerde anlamlı şekilde yüksekti (sırasıyla $p=0,007$ ve $p<0,0001$ ).

\section{Tartışma}

Günümüzde doğum öncesi dönemde riskli gebe ve fetüs önemli oranda saptanabilmekte ve doğumun risk düzeyine uygun merkezde yapılması sağlanabilmektedir. Ancak her zaman risk durumu önceden öngörülememekte ve doğumdan sonra bebeğin uygun merkeze gönderilmesi gerekmektedir (11-13). Tüm hastalarını dış merkezlerden sevkle kabul eden birimler için hastaların taşınma koşulları, ölüm ve sakatık başta olmak üzere sosyal ve hukuksal olaylar açısından çok önemlidir. Çalışmamız Diyarbakır ve çevresinde hasta yenidoğanın taşınma koşullarını düzeltmeye yönelik yapılan çalışmaların, YYBB'ye sevk edilen hasta yenidoğanlar üzerine olan etkilerini değerlendirmek amacıyla yapıldı.

1901 yllında Chicago'da Dr. Joseph B. De Lee tarafından ilk taşıyıcı kuvözün, 1906 yılında yine Chicago'da ilk motorlu ambülansın kullanıldığı zamandan günümüze hasta yenidoğanın taşınmasında büyük ilerlemeler olmuştur $(14,15)$. Ambülanslar, ve taşıyıcı kuvözler hasta yenidoğanın taşınması sırasında beden sıcaklığının korunması için vazgeçilmez öğeler olarak kullanılmaya devam etmektedir. Elverişsiz şartlarda yapılan taşınma sırasında en fazla karşılaşılan sorun hipotermi olup, ölüm ve sakatlık oranlarını artıran önemli bir etmendir $(16,17)$. Ülkemizde geçmiş yıllarda yapılan çalışmalarda hastaların ambülansla taşınma oranının \%11-\%81 gibi oldukça geniş bir aralıkta olduğu, ancak \% $7,8^{\prime}$ inin taşıyıcı kuvöz ile sevk edildiği ve hastaların \%18-\%74'ünün hipotermik olarak getirildiği bildirilmektedir (18-21). Çalışmamızda hasta yenidoğanın taşınma koşullarını iyileştirme çalışmaları sonrasında ambülansla sevk edilen hasta oranının \%55,8'den \%91,4'e ve taşıyıcı kuvöz ile sevk edilen hasta oranının ise \%39,1'den \%86,1'e yükseldiği dikkati çekmektedir. Çalışmamızda ambülansla ve taşıyıcı kuvöz eşliğinde yapılan taşıma oranındaki artışın sonucu olarak yenidoğanlarda hipotermi görülme sıklığı da azalmıştır (\%78,4'e karşı \%22,6). Değişen bu durumun taşıma sırasında kullanılan tıbbi aletlerin alımına ve hizmet içi eğitimler neticesi hasta yenidoğanın taşınmasının daha iyi koşullarda gerçekleştirilmesi bilincinin kazanılmasına bağlı olduğunu düşünmekteyiz.

Hipoglisemi yenidoğanda ölüm ve ciddi sakatıklara neden olabilen en önemli metabolik sorundur. İntravenöz sıvının takılmayışı, takılan sıvının uygunsuzluğu, yeterli miktarda sıvının

Tablo 3. Hastaların sevk tanıları

\begin{tabular}{|l|c|c|c|}
\hline Tanilar & 1. grup $(\mathbf{n = 1 5 2 5 )} \mathbf{n}(\%)$ & 2. grup $(\mathbf{n}=\mathbf{9 2 7}) \mathbf{n}(\%)$ & $\mathbf{p}$ \\
\hline Solunum sorunları & $551(36,1)$ & $311(33,5)$ & 0,194 \\
\hline Erken doğum & $350(23)$ & $188(20,3)$ & 0,121 \\
\hline Perinatal asfiksi & $201(13,2)$ & $143(15,4)$ & 0,120 \\
\hline Sepsis & $163(10,7)$ & $98(10,6)$ & 0,928 \\
\hline Diğer durumlar & $260(17)$ & $187(20,2)$ & 0,057 \\
\hline
\end{tabular}

Tablo 4. Hastaların taşıma koşullarına ait özellikleri

\begin{tabular}{|c|c|c|c|}
\hline Özellikler & 1. grup $(n=1525)$ & 2. grup $(n=927)$ & $p$ \\
\hline Taşıma öncesi haberleşme* & $16(1)$ & $246(26,5)$ & 0,0001 \\
\hline Yeterli epikriz varlığı ${ }^{*}$ & $140(9,2)$ & $373(40,2)$ & 0,0001 \\
\hline Ambülans ile taşıma* & $851(55,8)$ & $847(91,4)$ & 0,0001 \\
\hline Transport küvöz ile taşıma* & $596(39,1)$ & $798(86,1)$ & 0,0001 \\
\hline Doğum raporu varlı̆̆ı* & $940(61,6)$ & $863(93,1)$ & 0,0001 \\
\hline Kimlik ve cinsiyet bilgileri ${ }^{*}$ & $966(63,3)$ & $886(95,6)$ & 0,0001 \\
\hline Venöz yol açıklı̆ı̆ı & $946(62)$ & $855(92,2)$ & 0,0001 \\
\hline Entübe edilerek getirilen hasta* & $168(11)$ & $153(16,5)$ & 0,0001 \\
\hline Dolaşım bozukluğu varlığı* & $123(8,1)$ & $53(5,7)$ & 0,029 \\
\hline Hipotermi varlığı * & $1195(78,4)$ & $210(22,7)$ & 0,0001 \\
\hline Hipoglisemi varlı̆̆ı * & $560(36,7)$ & $90(9,7)$ & 0,0001 \\
\hline Hipotansiyon varlı̆ıı * & $156(10,2)$ & $69(7,4)$ & 0,02 \\
\hline TRIPS skoru** & $20,07 \pm 13,41$ & $12,89 \pm 11,53$ & 0,0001 \\
\hline
\end{tabular}

* Sonuçlar n (\%) şeklinde sunulmuştur

** Değerler ortalama, \pm SS olarak verilmiştir 
verilmeyişi ve özellikle de hipotermi gibi nedenler taşıma sırasında hipoglisemiye yol açmaktadır (22). Tekin ve ark. (19) çalışmalarında hastaların \%63,3'ünde, Gülez ve ark. (20) ise $\% 77,2$ 'sinde damar yolunun açık olmadığını saptamışlardır. Türkyılmaz ve ark. (21) şehir dışından sevk edilen bebeklerin \%32'sinde, Gülez ve ark. (20) ise \%31,2'sinde hipoglisemi saptamışlardır. Ülkemizde daha önce yapılan çalışmalardak sonuçlara benzer olarak, çalışmamızda birinci gruptaki bebeklerin \%36,7'sinde hipoglisemi saptandı. Hastaların \%41,6'sına sıvı takılmadığı, takılan sıvıların \%14,2'sinin ise yenidoğan için uygun olmadığı görüldü. Hasta yenidoğanın taşınma koşullarını iyileştirme çalışmaları sonrasında bu oranların anlamlı olarak olumlu yönde düzeldiği saptandı.

Yenidoğanlarda taşıma sırasında dolaşımın bozulması diğer önemli bir sorundur. Taşıma sırasında sorun olabilecek durumlar önceden düşünülmeli ve yaşamsal bulguların dengede olması sağlanmalıdır. Tekin ve ark. (19) sevk edilen yenidoğanların \%46,2'sinde dolaşım bozukluğu, \%56,8'inde oksijen desteği olduğu ve \%3'ünün entübe edilerek sevk edildiğini belirlemişlerdir (19). Benzer sonuçların elde edildiği çalışmamızda hasta yenidoğanın taşınma koşullarını iyileştirme yaklaşımları neticesinde hipotansiyon ve dolaşım bozukluğu görülme sıklığının azaldığı ve entübasyon gereksinimi olan hastaların entübe edilebilme sıklığının ise arttığı saptandı. Bu olumlu gelişmelerin, daha önceki çalışmalarda da vurgulanan sağlık çalışanlarına hizmet içi eğitimlerin (taşıma ve YCP) verilmesine, hastaların hipotermiden korunmasına ve tıbbi alet kullanımının artışına (ambülans, taşıyıcı kuvöz, nabız oksimetresi ve intravenöz sıvı pompaları) bağlı olduğunu düşünüyoruz $(23,24)$.

Hasta yenidoğanların nakledildikleri merkeze teslim edildiklerinde beraberlerinde öykü ve klinik seyir, sevk edilen merkezde yapılan tetkik, tedavi ve girişimlere ait bilgilerin yer aldığı hekim tarafından hazırlanmış yazılı bir belge bulunmalıdır. Bu yazılı belge yanında hastanın kimlik ve cinsiyetlerini belirleyici bilgiler yer almalı ve taşıma öncesi haberleşme mutlaka gerçekleştirilmelidir (25). Ülkemizde halen doğum raporu, hastaların kimlik ve cinsiyet verileri ve yazılı sevk bilgilerini içeren epikriz kağıdının standardizasyonunu sağlayan resmi bir düzenleme yoktur. Standardize edilmeyen hasta sevklerinin sadece tıbbi değil sosyal ve hukuksal (hastaların karışması, cinsiyetlerinin yanlış tespit edilmesi gibi) sorunlara da yol açtığı bilinmektedir (26). Çalışmamızda taşıma öncesi haberleşme eksikliği (servis iş gücünü ve düzenini bozan), yazılı epikriz bilgisinin olmaması (tıbbi veri eksikliğine ve hastaya yaklaşımda gecikmeye neden olan), doğum raporu ve kimlik-cinsiyet belirleyici verilerin bulunmaması (hukuki karışıklıklara yol açan) durumlarının saptanma oranı ikinci grupta azalmıştır. Bu olumlu sonuçlar; hizmet içi eğitim toplantılarına, birimimiz tarafından hazırlanan hasta yenidoğanın taşınmasında kullanılan nakil kağıdının sağlık bakanlığı resmi genelgesi ile bölgemize yönelik olarak hayata geçirilmesine ve yaşanan olumsuz hukuksal deneyimler sonucunda sevkleri gerçekleştiren merkezlerde çalışanların konu üzerinde duyarlııklarının artışına bağlı olabilir.

Taşıma öncesi ve sırasında "5 H kuralı" (hipotermi, hipotansiyon, hipoglisemi, hipoksi ve hipo-hiperkarbi) unutulmamalıdır (27). Taşıma öncesi ve sırasında sağlık ekibinin dikkat etmesi ve düzeltmesi gereken sorunları hatırlatmak için kullanılan bu ifadede yer alan hipotermi, hipotansiyon ve hipoglisemi hasta yenidoğanın taşınması koşullarının düzel- tilmesine yönelik gerçekleştirilen çalışmalardan sonra daha az oranda saptanmıştır. Bu da gerçekleştirilen uygulamaların etkin olduğunu ortaya koymaktadır. Ayrıca hasta yenidoğanın taşınması koşullarının iyileştirilmesi amacıyla gerçekleştirilen çalışmalardan sonra TRIPS skorunun olumlu yönde düzelme kaydetmesi ve ilk yedi gün ve genel ölüm oranlarının anlamlı olarak düşmesi bu düşünceyi destekler nitelikte önemli bulgulardır. Yine bu düşüncelerimiz taşıma sisteminin kurulmasından sonra yenidoğan merkezlerindeki ölüm ve sakatlık oranlarının düştüğünü bildiren literatür bilgileriyle de örtüşmektedir $(28,29)$.

Diyarbakır'daki yenidoğan bebek ölüm hızının oldukça yüksek olduğu (binde 20) ve hasta yenidoğanın taşınma koşullarının istenen düzeyde olmamasının bu oranın yüksekliğinde etkili olduğu bilinen bir gerçektir $(30,31)$. Bu nedenle hasta yenidoğanın taşınma koşullarının birçok çağdaş ülkede olduğu gibi bilimsel ve uzman oluşumlar tarafından ele alınması ve ülke sağlık politikalarında yer alarak bölgeselleştirilme örneği ile yönetilmesi kaçınılmazdır (32,33).

Sonuç olarak bu çalışma ile birimimize sevk edilen hasta yenidoğanların taşınma koşullarının bir dizi uygulamalar ile düzelebildiği saptanmıştır. Bu çabanın perinatal bakımın bölgeselleşme çalışmaları olmadan, bölgedeki yenidoğan ölüm ve sakatlık oranlarının istenilen düzeylere getirilmesinde yeterli olamayacağını düşünüyoruz. Perinatal bakımın bölgeselleştirilmesinin temel ayağı olan hasta yenidoğanın taşınması sisteminin akılcı koşullar sağlanarak oluşturulması kavramı, temel sağlık politikalarında acil eylem planı olarak ele alınmalıdır.

\section{Çıkar çatışması: Bildirilmemiştir.}

\section{Kaynaklar}

1. American Academy of Pediatrics. American College of Obstetricians and Gynecologists. Organization of perinatal health care. In: Lockwood CJ, Lemons JA, ed(s). Guidelines for Perinatal Care. 6th ed. Elk Grove Village, IL: American Academy of Pediatrics; 2007: 1-18.

2. Lupton BA, Pendray MR. Regionalized neonatal emergency transport. Semin Neonatol 2004; 9: 125-33.

3. Butterfield LJ. Historical perspectives of neonatal transport. Pediatr Clin North Am 1993; 40: 221-39.

4. Papiernik E, Breart G, Di Renzo GC, et al. Introduction to the European Network for Perinatal Transport (EUROPET) Project. Prenat Neonat Med 1999; 4: 1-4

5. Debauche C, Van Reempts P, Chabernaud LJ, et al. Maternal and neonatal transfer policies in Europe. Prenat Neonat Med 1999; 1: 5-14.

6. WHO thermal control of the newborn: a practicle guide. (Maternal Health and Safe Motherhood Programme) Geneva; WHO, 1993: 15-31.

7. Cornblath $\mathrm{M}$, Hawdon JM, Williams AF, et al. Controversies regarding definition of neonatal hypoglycemia: suggested operational thresholds. Pediatrics 2000; 105: 1141-5.

8. Seri I, Evans J. Controversies in the diagnosis and management of hypotension in the newborn infant. Curr Opin Pediatr 2001; 13: 116-23

9. Evans N, Seri I. Cardiovascular compromise in the newborn infant. In: Taeusch HW, Ballard RA, Gleason CA, (eds). Avery's diseases of the newborn. 8th ed. Philadelphia: Elsevier Saunders, 2005: 398- 409.

10. Lee SK, Zupancic JA, Pendray M, et al. Canadian neonatal network. Transport risk index of physiologic stability: a practical system for assessing infant transport care. J Pediatr 2001; 139: 220-6.

11. Richardson DK, Reed K, Cutler JC, et al. Perinatal regionalization versus hospital competition: the Hartford example. Pediatrics 1995; 96 : 417-23.

12. James AG. Resuscitation, stabilization, and transport in perinatology. Curr Opin Pediatr 1993; 5: 150-5. 
13. Greene WT. Organization of neonatal transport services in support of a regional referral center. Clin Perinatol 1980; 7: 187-95.

14. Lee JBD. Infant incubation, with the presentation of a new incubator and a description of the system at the Chicago lying-in hospital. Chicago Medical Recorder 1902; 22: 22-40.

15. Haller JS Jr. The Ambulance: a history. J Hist Med Allied Sci 2009; 64: 392-4.

16. Ji XC, Zhu CY, Range RU. Epidemiological study on hypothermia in newborn. Chin Med J Engl 1993; 106: 428-32.

17. Kırımi E, Tuncer $\mathrm{O}$, Ataș $\mathrm{B}$, et al. Hipotermik yenidoğanlarda vital bulguların değişimi. Türk Pediatri Arşivi 2003; 38: 93-8.

18. Okan F, Uslu S, Nuhoğlu A. Yenidoğan kliniğine sevk ve transport edilen hastaların irdelenmesi. Çocuk Dergisi 2005; 3: 195-200.

19. Tekin N, Akşit A, Dinleyici EÇ, et al. Osmangazi Üniversitesi Tıp Fakültesi neonatoloji ünitesine başvuran yenidoğanların transport koşullarının değerlendirilmesi. Perinatoloji Dergisi 2001; 9: 230-4.

20. Gülez P, Kayserili E, Sarıtas T, et al. Yenidoğan Nakilleri. ADÜ Tıp Fakültesi Dergisi 2004; 5: 5-10.

21. Türkyılmaz $C$, Koç $E$, Atalay $Y$. Yenidoğan bebeklerde transport. Türkiye Klinikleri Pediatri Dergisi 1997; 6:24-8.

22. Fenton A, Leslie A, Skeoch CH. Optimising neonatal transfer. Arch Dis Child Fetal Neonatal Ed 2004; 89: 215-9.

23. Öztürk $A$, Büyükkayhan $D$, Köklü $E$. Perinatal ve neonatal dönemde yenidoğanın nakli. Erciyes Tıp Dergisi 2007; 29: 252-60.

24. Duran R, Aladağ N, Acunaş B. Bir olgu nedeniyle yenidoğan transportundaki sorunların irdelenmesi. STED 2005; 14: 247-8.
25. American Academy of Pediatrics. Section on Transport Medicine. Communications and the Dispatch Center. In: Woodward GA, Insoft RM, Kleinman ME, ed(s). Guidelines for air and ground transport of neonatal and pediatric patients. 3rd ed. Elk Grove Village, IL: American Academy of Pediatrics; 2007: 55-80.

26. Gill AB, Bottomley L, Chatfield S, et al. Perinatal transport: problems in neonatal intensive care capacity. Arch Dis Child Fetal Neonatal Ed 2004; 89: 220-3.

27. Buckland L, Austin N, Jackson A, et al. Excessive exposure of sick neonates to sound during transport. Arch Dis Child Fetal Neonatal Ed 2003; 88: 513-6.

28. Agostino R, Fenton AC, Kolle'e LAA, et al. Organization of neonatal transport in Europe. Prenat Neonatal Med 1999; 4: 20-34.

29. Moss SJ, Embleton ND, Fenton AC. Towards safer neonatal transfer: the importance of critical incident review. Arch Dis Child 2005; 90: 729-32.

30. Saka G, Ertem M, İçlin E. Diyarbakır Doğum Evi Hastanesi'nde doğum yapan gebelerde risk faktörleri: Ön çalışma. Perinatoloji Dergisi 2001; 9: 108-15.

31. The Hacettepe Institute of Population Studies. Turkey Demographic and Health Survey, 2008 (TDHS-2008). http://www.hips.hacettepe.edu.tr/tnsa2008/index.htm

32. Debauche C, Van Reempts P, Chabernaud JL, et al. Maternal and neonatal transfer policies in Europe. Prenat Neonat Med 1999; 1: 5-14.

33. Cornette L. Contemporary neonatal transport: problems and solutions. Arch Dis Child Fetal Neonatal Ed 2004; 89: 212-4. 